\title{
ANTIHEROÍSMO Y NIHILISMO EN LA OBRA LITERARIA DE ALBERT CAMUS
}

\section{NIHILISM AND ANTIHEROISM IN ALBERT CAMUS LITERARY WORK}

\author{
Luis González García. \\ Colegio Concepción, Chile \\ dialectica12@gmail.com
}

\begin{abstract}
Resumen:
El objetivo de este trabajo consiste en analizar desde la obra teórica y literaria del escritor francés Albert Camus( 1913-1960), la estrecha relación entre el anti heroísmo y el nihilismo que se establece bajo personajes que, desbaratados de trascendencia y gloria, advierten en su actitud taciturna y absurda un amenazante nihilismo subyacente en la ambigüedad moral que los sostiene. De esta manera, se pretende mostrar como Camus nos propone una original exhortación ética tras el componente nihilista inserto germinalmente en toda acción que se mueve entre la negación y la afirmación total; es decir, en la vana y ascética resignación como en el frenetismo por la recomposición absoluta de sentido.
\end{abstract}

Palabras claves: Anti heroísmo, nihilismo, absurdo, rebelión, ética.

\begin{abstract}
:
The aim of this work is to analyze from the theoretical and literary work of the French writer Albert Camus (1913-1960), the close relationship between the anti-heroism and the nihilism that is established under characters who, disrupted by transcendence and glory, warn in their taciturn and absurd attitude a threatening nihilism underlying the moral ambiguity that sustains them. In this way, it is intended to show how Camus proposes an original ethical exhortation after the nihilistic component inserted germinally in any action that moves between denial and total affirmation; that is, in the vain and ascetic resignation as in the frenetism by the absolute recomposition of meaning.
\end{abstract}

Keywords: Anti heroism, nihilism, absurd, rebellion, ethics.

Recibido: 11 de marzo de 2019

Aceptado: 19 de mayo de 2019 


\section{Introducción}

Ciertamente que el arquetipo del hombre moderno y contemporáneo ya no se reconoce moralmente en el acto ejemplar y virtuoso. El héroe de antaño, en relación a su acción modélica y redentora de lo éticamente corrompido, yace bajo los escombros de los "falsos dioses" por Nietzsche sentenciados y la postmodernidad constatada. De la estética romántica y el dandismo que ostentaban los "poetas malditos" queda sólo el vestigio del sentido de identidad universal subyacente en la denuncia dramática y lírica de un mundo que les resiste. Se desprende de ello que la modernidad no propicia virtuosismo ni univocidad de sentido suprasensible. El héroe ya no tiene a quién tributar en un cielo que se ha desmontado hasta en su inteligibilidad. Más bien la funcionalidad del hombre anónimo de la gran ciudad propia del siglo $\mathrm{XX}$, remite a eximirse de moralejas éticas trascendentales. Disuelta la unidad ética universal y con ello, las normativas morales absolutas o referenciales, pareciera que sólo se preserva la estética del héroe, pero cobijada en una actitud taciturna e in-esencial que prescinde de un para qué, que ya Friedrich Nietzsche consideraba como síntoma inequívoco de un nihilismo que asecha: "Nihilismo: falta el fin; falta la respuesta el ¿para qué? ¿Qué significa nihilismo? Que los valores supremos se desvalorizaron" (35).

Precisamente, lo que nos interesa analizar en este trabajo consiste en cómo ésta comprensión del nihilismo influirá en la figura de un antihéroe de overol, traje o levita que la literatura del siglo XX nos ilustrará con todas sus desavenencias y avatares existenciales, tal como lo examinaremos en la obra del escritor francés Albert Camus (1913-1960). Por lo mismo, desde un Camus lector de Nietzsche ${ }^{1}$ apreciaremos como este héroe desilusionado se embarca en un peregrinaje de in-trascendencia que desiste de todo afán de inteligibilidad; pues como afirma Antonia Birnbaum: "El Héroe desencantado no se ciega en su búsqueda de gloria, la luz horizontal sin jerarquía con la que baña el mundo cotidiano basta para alumbrar todas sus peregrinaciones" (12).

\footnotetext{
${ }^{1}$ Influencia nietzscheana que Camus nunca renegó; es más, para algunos analistas: “(...) la influencia más determinante en su vida fue Nietzsche, y así en sus novelas El Extranjero y La Peste, afrancesó a Nietzsche para beneficio de una generación entera de jóvenes franceses" (Johnson 580.)
} 
De esta manera, los antihéroes que observaremos en los personajes de Camus circularán en torno a un desbaratamiento de toda trascendencia, inherente al siglo XX. Será a la vez un desencantamiento que "triunfa" en su lucidez sobre la intrascendencia de su cotidianidad. Accionar desgarradamente asumido, enmarcado por fuerzas anónimas deterministas que disonantemente juzgan y la vez eximen de cierta responsabilidad moral. Antihéroes en tanto para Birnbaum, “indiferentes a las cuestiones esencial, aquello los vuelve tanto más predispuestos a lo imprevisible"(12). Prima en estos seres periféricos una indiferencia a lo esencial producto de una concesión a la lucidez y a lo imprevisible, como cualidades propias de las tipologías representados por Camus a través de su obra literaria como ensayística. En consecuencia, en este artículo trataremos de examinar al antihéroe en Camus, enfocados en sus problemáticas existenciales y morales, como en sus procesos de conversión nihilista, apreciados desde la actitud taciturna e indiferente del antihéroe absurdo hasta la resolutiva y purgativa acción del antihéroe rebelde camusiano. Para tales efectos de investigación nos atendremos a comparar ciertas obras en Camus de su primera etapa "mediterránea" unificadas con su etapa del pensamiento absurdo, como lo son Anverso y Reverso o El extranjero; para luego dar cuenta de sus obras ancladas en el ensayo El Hombre Rebelde, como serían La Peste y el Estado de Sitio entro otras obras anexas.

\section{Concesión a la lucidez: el absurdo.}

Haber nacido en Argelia, ser hombre del mediterráneo no era una cuestión menor para Albert Camus. Es más, se afirmaba que él exclamaba con cierto orgullo que su pensamiento tenía su fuente de origen en cierta "ideología mediterránea" que, contradictoriamente originada por hombres no mediterráneos como Oscar Wilde o Gide, sugerían una imagen cultivada de este norte africano que generaba la convicción de que en estas orillas bendecidas por el sol los hombres conocían la mesura y la justa medida de las cosas (Herbert 89). Es entonces que el absurdo como disonancia entre el ser humano y el mundo, tendría su fuente de origen en aquella sensibilidad nacida de una antagónica vida particular desenvuelta entre una pasión desbordada de vivir bajo el sol, el mar y las fragancias de una vida sensitiva; y por otra, la podredumbre de lo aparentemente inmerecido de una vida precaria y silente. De ahí la relevancia de su primera obra como 
testimonio de sus propias experiencias como "hijo del mediterráneo" plasmadas por ejemplo, en Anverso y Reverso o Bodas, de 1937 y 1939 respectivamente, que sustentarían sino una filosofía, sí una "sensibilidad" característica. En efecto, Camus rescataría desde tal vida mediterránea una interpretación existencial bajo la descripción de experiencias y vidas en lo que tienen de fútil e irrelevante. Yacería en estas expresiones literarias cierta prefiguración de una valoración moral a la luz del absurdo de la existencia, señalada como una aproximación al talante nihilista que ahondará posteriormente mediante sus personajes y escritos. El escritor francés representará aquel sentimiento de sosiego inasible y desolador, por ejemplo en Anverso y Reverso cuando describe una diversidad de vidas que confluyen en la desesperanza de una muerte cierta: "Una mujer que se abandona para ir al cine, un viejo al que ya no se le escucha, una muerte que no rescata nada y luego, al otro lado, la luz del mundo. Se trata de tres destinos semejantes $\mathrm{y}$, sin embargo diferentes. La muerte para todos, pero para cada cual su muerte" (64).La no-correspondencia del mundo frente a la interrogación humana somete al ser humano en la soledad y angustia más implacable, pero exhortaría a desprenderse de la ilusión, de la esperanza que sostendría un "pode-ser" constantemente inconsumado: "la esperanza, al contrario de lo que se cree, equivale a la resignación. Y vivir es no resignarse" (127).

Es así que estos personajes se nos presentan como antihéroes, en tanto frecuentan desengañadamente un absurdo agobiante, transando sus experiencias en desilusiones y contrastes que colisionan con sus vanas esperanzas; no obstante, triunfan en el conocimiento de dicha adversidad. Constatación de lo absurdo que se presentaría como una contradictoria lucidez ofrecida a un espíritu que, forjado en el mediterráneo, cultivó sensibilidad y férrea conciencia: "el mediterráneo exige almas clarividentes, es decir, sin consolación. Pide que se haga un acto de lucidez, lo mismo que se hace un acto de fe" (Camus, Bodas 105). Por eso Camus en su época "mediterránea" nos ofrece una desengañada mirada de la condición humana que no podía sino exigir el silencio, el mutismo cómplice de asombro e indiferencia frente a una realidad que desborda; como si el silencio fuera la mejor expresión de la amenaza del nihilismo sobre estos antihéroes que eran parte de su propia vida. En su libro póstumo El Primer Hombre el escritor francés nos dará cuenta de tales silentes siluetas que frecuentaron su infancia en Argelia: “Así cada vez que me ha parecido sentir el sentido profundo del mundo, es su sencillez lo que me ha 
conmovido siempre. Mi madre, aquella noche, y su extraña indiferencia" (194). Desembarazo de certidumbres suscitada por la madre analfabeta, el padre ausente, más una pobreza lacerante como marco social. Sensibilidad nihilista si bien no declarada por el escritor francés en sus comienzos, sí se traducirá en su obra como una especie de testimonio de humanidad consciente, como lo declara en Anverso y Reverso: "El mundo es hermoso, y fuera de él no hay salvación” (140).

Sin embargo, la conciencia de lo disonancia del mundo de estos antihéroes ocultaría para Camus una valoración moralizante más que puramente de-veladora o meramente estética. Tal interés lo establecerá en el Mito de Sísifo ${ }^{2}$ publicando en 1942. Ensayo que representaría, contradictoriamente, un proceso de "moralidad" progresiva dentro de su obra posterior. Afirma en tal libro, a modo de formulación de principios: "Juzgar que la vida vale o no vale la pena de que se la viva es responder a la pregunta fundamental de la filosofía" (15). Es que suicidarse para nuestro autor supone: "confesar que se ha sido sobrepasado por la vida o que no se comprende ésta" (17). Parece ser la respuesta última a los antagonismos señalados como un sin-sentido y que acontecen mediados por un razonamiento que encontrará sus axiomas en una interrogación desesperada. Arrojarse a la obnubilación de suicidarse sería por consiguiente, evadir una realidad no por desestimar la vida en sí; sino porque más bien se encuentra ésta indigna de vivirla con tales antagonismos. Empero, ello de igual forma implica esclarecer para el Nobel francés: “¿El absurdo impone la muerte?"(21). Tal revelación de una existencia desvelada de su afán de “ser” lo ilustraría Camus en El Extranjero de 1942, por medio de Meursault. Precisamente este personaje, antihéroe por excelencia, es un "extraño" desbaratado de un afán de trascendencia, des-acostumbrado y desarraigado del profundo sentido humano. Tal es el desarraigo de corte nihilista que embarga a Meursault, que incluso la estimación valórica y emocional de la muerte de su madre quedaría reducido a una nimiedad que no sobrepasará en mucho la significación de lo realizado habitualmente: "Pensé, que al cabo, era un domingo de menos, que mamá estaba ahora enterrada, que iba a volver a mi trabajo y que, después de todo, nada había cambiado” (30). De este modo Camus nos deja entrever,

\footnotetext{
${ }^{2}$ Este ensayo representaba para Camus el tratamiento teórico de aquella "sensibilidad" absurda expresada narrativamente en obras como El Extranjero, Calígula o El Malentendido.
} 
según estimamos, que el antihéroe será aquel que se caracteriza por lo inmotivado de sus acciones rutinarias, entregadas a la inercia de un anonimato. Existencia caída en la mundaneidad como comprensión fáctica cara a Heidegger: “(...) en la caída no está en juego sino el poder- estar- en- el- mundo, aunque en modo de la impropiedad" (203). Inserto en lo impropio, sin arraigo y pertenencia, el deambular inexpresivo del $E l$ Extranjero concibe y transa silentemente el mundo y los seres humanos, como si ninguna palabra o lenguaje podrían sondear la inefable orfandad de referentes: "Un hombre habla por teléfono detrás de un tabique de vidrio, no se le oye, pero se ve su mímica sin sentido: uno se pregunta por qué vive” (27), nos dice Camus en el Mito de Sísifo. En el mismo ámbito, Meursault desarraigado de la serialidad moral, "sólo se limita a contestar las preguntas" (Carnets II 25). Su acción cotidiana, "pantomima absurda", se ofrece como consecuencia de fuerzas alienantes que le sostienen en el automatismo de una vida ordinaria e intrascendente. Automatismo que parece situarlo en la fecunda relación humana; no obstante, la languidez y la actitud lacónica enquistadas como ethos personal circunscriben todo acto inter-subjetivo cerrando el paso al genuino acogimiento del otro. Así le ocurre a Meursault con Marie: "Cuando se ríe la deseo más. Un momento después preguntó si la quería. Le respondí que eso no significaba nada, pero que me parecía que no. Su expresión fue triste" (El Extranjero 40).

La actitud taciturna de Meursault renunciando a las grandes verdades evidencia la opción del antihéroe camusiano, pero también un intento de recomposición de una tensional "valoración moral" contradictoriamente iconoclasta y nihilista. Valoraciones sustentadas en introspectivas interrogaciones de alcances morales y metafísicos. De ahí que, como afirma el filósofo italiano Franco Volpi, en los personajes existencialistas, especialmente en Camus, se frecuente una autoconciencia como una suerte de original gnosis: "Quien tiene en cambio plenamente presente la estructura gnóstica subyacente a su propia reflexión existencialista y nihilista es Camus" (123). Gnosis que según Volpi se desenvuelve a escala de constatación de una orfandad moral y cósmica, proyectándose en que los personajes de la literatura existencialista "se concentran en una trágica descripción de desarraigo y extravío de la existencia mortal” (121). Introspección como manifestación de una oculta redención que fortalece paradojalmente en tal intento emancipatorio, un nihilismo lacerante en sus intentos de superación de tal abyecta condición. Por eso bajo la 
perspectiva del filósofo italiano, contextualizable a nuestro análisis en Camus, es inherente a los personajes existencialistas interrogantes sin correlato ni garantías de verdades, como testimonio de su soledad cósmica que lo lleva a plantearse: “¿qué somos? ¿de dónde venimos? ¿Adónde vamos?’(121).

Así el absurdo sería la contemplación y evidencia descarnada de una pantomima carente de sentido, de una segregación de inhumanidad proveniente del hombre y el mundo, y que para nuestro autor francés volvería insulso cuanto le rodea. Pero apresuradamente se podría aseverar que el absurdo es la realidad, el mundo o el hombre. Más bien para Camus, "el absurdo no está en el hombre, ni en el mundo, sino en su presencia común" (El Mito 43). Por ende, el absurdo como componente del anti heroísmo sienta su presencia en la moderna asimilación de acciones automatizadas gobernadas por fuerzas anónimas, subsumiendo al sujeto en una inercia amoral que contradictoriamente lo eximen de su responsabilidad ética o compromiso inter-subjetivo con los otros. Y es que llegado el momento- y Camus lo explícita en sus Carnets- prontamente dicha convergencia de intereses comunes se diluye cuando cobramos repentina conciencia de que estamos siempre atados a los otros y a sus preceptos, y con ello a la amarga posibilidad de su no correspondencia: "Aquellos seres, llegado un momento, nos dan la espalda; rompen con nuestras expectativas de ser. Se quería ignorar que mantenían siempre la posibilidad de interesarse por otra cosa" (60). Es por ello entonces que la lucidez del anti heroísmo absurdo parece lacerar no sólo por la denuncia de cierta incongruencia cósmica y existencial; sino también por el terrible sosiego de orfandad moral que imposibilita levantar la mirada hacia los otros precedidos por una genuina valoración humana.

No obstante lo anterior, el anti heroísmo absurdo, degradante y solipsista, en tanto desembarazo de esas formas estables de resonancia nietzscheanas; podría como lo afirma Gianni Vattimo, respecto a al nihilismo en sí mismo, pretender solventar bajo tal inclinación una no- verdad de ineludible sentido moral (122). En efecto, si bien Camus no desconoce dichos alcances valorativos del absurdo en cuanto actitud lúcida y desfundamentadora propia del anti heroísmo que representa Sísifo; ello no bastaría para formular una regla de acción ética más fecunda que logre defender más sustancialmente la vida y la sociedad humana. Por consiguiente, desde la perspectiva de una necesaria exhortación ética que enfrente el nihilismo inherente a la condición humana: o se trataría 
de la continuidad en el mundo uniforme y serial, con lacónica y ambigua expresión, o acontece un despertar definitivo fundador de un nuevo comienzo en sostén de perspectivas éticas que logren resistir tal nihilismo.

\section{El anti heroísmo rebelde y el nihilismo.}

Bajo el contexto de una progresión y ahondamiento de un "relato ético" en su obra creativa y especulativa, sería en El Hombre Rebelde publicado en 1951 en donde podemos observar como Camus representaría una más clara exigencia moral montada sobre ésta misma figura del antihéroe que estamos examinando. La vociferación de un sentido extraviado antes inexpresiva, pero sensibilizada en un talante, ahora es proyectada en la conciencia de un flagelo común inapelable: el mal. Y precisamente, frente el absurdo trasmutado en el mal, la "Peste" aparece como símbolo de un escarnio existencial propagado a todos los seres humanos por igual. El rebelde, fiel a la lucidez y a la defensa ética, acusa el no derecho a infringir cierto límite axiológico. Reivindicación necesaria en torno a un valor en común que debe ser preservado y del cual nadie tiene derecho a menoscabar: "¿Qué es el hombre rebelde? Un hombre que dice no. Pero si rechaza, no renuncia: es también un hombre que dice sí, desde su primer movimiento" (El Hombre 17). Por ende, la rebelión es en el ser humano el rechazo a ser a ser rebajado ontológicamente como cosa u objeto. Es más, la misma rebelión coloca a Camus en el ámbito de la sospecha de la presencia de una naturaleza común ${ }^{3}$ a toda la humanidad, pues entonces: “¿por qué rebelarse si no hay nada permanente que conservar?”(17). Especie de imperativo que prevalece como defensa de un derecho, Camus lo entiende contrariando al "cogito cartesiano" como "Me rebelo, luego somos" (26), que en cierto modo nos ilustra la fuerte implicancia moral de la rebelión poseedora en sí misma de una carga axiológica relevante. En consecuencia, en la rebelión "el hombre se supera en sus semejantes" (20) y desde este punto de vista, "la solidaridad humana es metafísica" (20). Y es que revelado contra el absurdo, el rebelde extrema su defensa universal "querellándose" contra Dios por su flagrante amparo de la muerte y el mal concebidos primigeniamente bajo su voluntad.

\footnotetext{
${ }^{3}$ La explícita afirmación de una naturaleza humana, de un valor estable y esencial, sería para Camus una de las la ideas que fundamentaría su demarcación del movimiento existencialista que pregonaba principalmente Jean Paul Sartre bajo su formulación de principios "la existencia precede a la esencia".
} 
Encararía su indiferencia ante el dolor humano que se muestra del todo incongruente con su voluntad impregnada de amor y justicia.

De esta manera acontece un nihilismo pasivo como desembarazo estéril de los relatos o verdades suprasensible (heideggerianamente entendido) que se consuma irónicamente en una nostalgia de los referentes perdidos. En torno a ello Camus nos afirma: "si es destino no está orientado por un valor superior, si el azar es rey, se trata de la marcha en las tinieblas, de la horrible libertad del ciego" (70) nos dice un Camus lector crítico de Nietzsche. Se desprende que el afán y obsesión rebelde de reposición de sentido embriaga al antihéroe; prescinde de la tensión entre el sí y no propia de la auténtica rebeldía. Conforme a ello, la comprensión absurda de la existencia trasmutada en rebeldía contra el mal, tal como nos ilustra Camus, se ofrecería más bien como un cierto "retiro del mundo" como si estuviera ad portas de aquel ideal ascético que Nietzsche comprendía amenazante cuando nos afirmaba en su Genealogía de la Moral : "Pues justamente esto es lo que significaba el ideal ascético: que algo faltaba, que un vacío inmenso rodeaba al hombre"(204).Vacío insoportable y degradante que exige sentido, contrariando con ello una condición natural, pues para filósofo alemán: “el hombre, el animal más valiente y más acostumbrado a sufrir, no niega en sí el sufrimiento, lo quiere, lo busca incluso"(204). Empero, contrariando la crítica genealógica nietzscheana, de igual forma en la cultura occidental termina naturalizándose la exclamación desesperada del "para qué vivir" que resuena como trasfondo del sinsentido, como reacción ascética de salvación: "La falta de sentido del sufrimiento, no éste mismo, era la maldición que hasta ahora yacía extendida sobre la humanidad, iy el ideal ascético ofreció a ésta un sentido"(204). Sed de sentido y metas que para el mismo Nietzsche constituía la voluntad cuando ésta "prefiere querer la nada a no querer (205). Es el nihilismo como voluntad irrefrenable la que seduce al mismo antihéroe. En efecto, para el escritor francés las negaciones fundamentales, constatadoras de la incongruencia del mundo se trastocan por afirmaciones incontenibles, frenéticas alocuciones de verdad. El desquiciado Calígula nos pone en alerta en la obra homónima de Camus: "Este mundo, tal como está hecho, no es soportable. Así que necesito la luna, la felicidad o la inmortalidad" (718). Desprovisto de trascendencia, en la inmanencia, en el examen introspectivo sólo encuentra afán totalitario de afirmación plena; vehemencia por una fundación frenética del sentido extraviado. Se desprende que moralmente Camus se 
pregunte: “¿Se puede lejos de lo sagrado, de sus valores absolutos, encontrar una regla de conducta? (El Hombre 25). En consecuencia, paradojalmente "todo está permitido y los siglos del crimen se ha preparado para este minuto de trastorno" (61). Esa añorada emancipación que se anuncia en la plasmación estética- literaria por medio de los reflexivos personajes de Dostoievski, entrará en función como consagración de una contradictoria libertad con la sentencia de la "muerte de Dios" que Nietzsche exclamaba como diagnóstico de una decrepitud nihilista pronta a advenir.

Es la rebelión infiel a sí misma consumada como nihilismo que para Camus implicaría sobre todo "voluntad de desesperar y de negar" (58). Y es que siendo el nihilismo foco de interpretaciones diversas, Camus no podía ignorar la "nihilidad" inherente implicada en desasirse de referentes que frecuentaba una conciencia metafísicamente constituida. El nihilismo que el escritor francés menciona infatigablemente, pero que no define de manera exhaustiva, parece entenderlo a la luz de presupuestos innegablemente nietzscheanos. Por lo mismo, el desembarazo y la degradación de una directriz metafísica y moral traslucida en los personajes de Camus nos da cuenta de una no-ultimidad de la conciencia que no podría prescindir posteriormente de preparar una futura resurrección. La nostalgia por el "cadáver de Dios", reinar en función del "trono vacío" son señales del luto peregrino por la verdad fenecida. Por eso lo que Nietzsche constata, lo explícita y deduce el mismo Camus: "Sin Dios ¿Cuál es el fundamento de la moral? Se niega a Dios en nombre de la justicia, ¿pero la idea de justicia se comprende sin la idea de Dios? ¿Absurdo?” (58). El rebelde después de la blasfemia contra Dios que implicaba un "no" rotundo, afirmará al unísono un "sí" categórico que lo llevaría a confundir la "Unidad" con la "Totalidad". El principio de unificación moral necesario implica ahora lo universal sin restricciones. El "todo" y el "sí" iracundo debería ser el signo de la consumación de una humanidad reencontrada consigo misma. La Historia será ahora el cobijo de este sueño de la justicia y el bien absoluto, nos señala Camus. Así el antihéroe rebelde amparado en el nihilismo "después de huir de la prisión de Dios, su primera preocupación será construir la prisión de la historia y de la razón” (78).

Para el Nobel francés el bien y el mal aparecen ahora como juicios de ostentación pseudo moral de utilidad o ineficacia, que es también el discurso de quién se autoproclama la misión heroica de la redención universal. Queda de tal manera la sensación de que nada 
es bueno o malo, sino prematuro o caduco. En tal sentido, en la obra El Estado de Sitio estrenada en 1948 se perpetúa la eximición moral individual y social en base a la legalidad impuesta de la muerte. El antihéroe trasmutado por su frenetismo de expiación frenética promete extinguir el mal sirviéndose del nihilismo para su empresa inquisidora. El antihéroe es ya ahora un dictador o un inquisidor que emancipará de los malos augurios. El resto de los seres humanos se sacude de su letanía quedando a merced de sus resquicios de odio reprimidos, revividos por un discurso eminentemente nihilista, socialmente instalado. Afirma un habitante anónimo del pueblo en El Estado de Sitio: "que buena ocasión para liquidar a esos hijos de perra que se han atiborrado mientras nosotros reventábamos de hambre" (1044). La muerte, el mal son amparados por el marco racional, argumento nihilista que fundamenta el mal en la costumbre y la ley. Lo confirma el Juez en la misma obra de teatro señalada: "Si el crimen se convierte en ley cesa de ser crimen" (1005). El lenguaje es oscuro y ambiguo, dando paso al silencio y el acatamiento mudo y cómplice, incluso sancionando la virtud como repara nuevamente el Juez: "En efecto, hay que castigarla si tiene la arrogancia de discutir la ley" (1055).

\section{El antihéroe y la "superación" del Nihilismo.}

El nihilismo dentro del universo literario de Camus, así como alcanza su plenitud en el contexto de personajes que ostentan la nostalgia errada de un redentor que purgue todo mal y absurdo universal; a su vez abre el paso desde las circunstancias del flagelo, para una reconversión asumida como una reivindicación axiológica gracias a una lucidez sin concesiones. Camus mediante los antihéroes devueltos a la mesura de la lucidez, nos dejara ver que si bien el mal, la injusticia o la muerte son una realidad a enfrentar, la pretensión es asimilar la imposibilidad de su erradicación definitiva, la de negar las justificaciones que yerguen a la muerte y la destrucción en opciones válidas de reinstauración. Más bien para el escritor francés una comprensiva y mesurada demanda sería "proponerse la disminución aritmética del dolor en el mundo...pues la injusticia y el sufrimiento subsistirán y, por mucho que se los límite, no dejarán de ser un escándalo" ( $E l$ Hombre 280).El antihéroe rebelde consciente de la realidad beligerante no reniega su condición moral antagonista. La rebelión se alza con la preconcebida idea de lo irrevocable del destierro definitivo de una realidad adversa, por lo que el intento es "sólo" disminuir la 
propagación del mal. Por consiguiente, esa referencia moral se ofrece para este antihéroe rebelde como “(...) el único valor que puede salvarnos del nihilismo: la larga complicidad de los hombres en lucha con su destino" (262).

El antihéroe rebelde que reivindicaría en Camus un orden moral, logrando atenuar el absurdo que representa el mal y el nihilismo, creemos apreciarlo en el doctor Rieux de La Peste: “¿No es cierto, puesto que el orden del mundo está regido por la muerte, que acaso es mejor para Dios que no crea uno en él y que luche con todas sus fuerzas contra la muerte, sin levantar los ojos al cielo donde él está callado? (110). Siempre va a ser del todo incomprensible para el rebelde Rieux que el Dios del amor deje morir sin justificación pese a la entrega ferviente exigida por tal divinidad, aun en las desgracias más incomprensibles. Este médico ateo se lo hace ver con claridad al sacerdote Paneloux, voz de Dios en la tierra: "No, padre - dijo -. Yo tengo otra idea del amor y estoy dispuesto a negarme hasta la muerte a esta creación donde los niños son torturados” (182). Precisamente, RieuxCamus dice poseer otra idea del amor que, contraria a esa resignación que él aprecia en la inacción y esperanza infecunda del sacerdote, sería eficaz y de acción positiva. Tal valor gestado en la rebelión ante el absurdo sería la fraternidad, que liga a los seres humanos de un mismo destino entrelazándolos en una promesa de vida y la posibilidad siempre latente de la muerte. La fraternidad en efecto, es el móvil oculto pero indispensable de la acción eficaz del rebelde que convoca a la acción concreta de solidaridad con los hombres enfrentados a los caprichos del destino. Y es que en última instancia la caridad nacería de ese amor para con Dios que no posee ese origen en el círculo humano que hace surgir la fraternidad (Gallardo 16).

Es por eso que Rieux de La Peste, Diego de El Estado de Sitio, y en parte Meursault de El Extranjero, son tipologías de los antihéroes camusianos que nos dan señales de tal intento de superación nihilista bajo la conciencia de las barreras infranqueables de la muerte y el mal. Meursault le imprecaba al capellán, invocando su desengañada comprensión de la vida en torno a ilusorias esperanzas, que por lo menos: “ninguna de sus certidumbres valía un cabello de mujer...pero yo estaba seguro de mí, seguro de todo, más seguro que él, seguro de mi vida y de esa muerte que iba a llegar"' $E l$ Extranjero 122). Diego por su parte, el antihéroe rebelde de El Estado de Sitio, ávido de comunicar expresa que "lo que cuentan son las razones de mi vida. No soy un perro" 
(1050). La lucidez de Diego implica asumir el nihilismo y refrendar en la paradoja de lo trágico y su asimilación, la plataforma de rebelión heroica en torno a la conciencia de lo relativo de una acción ejemplar sin garantías. La concesión a una desgarrada lucidez fue el precio que pagará incluso con su vida. Encara la muerte como tragedia natural que rechaza la lógica y el odio como su lev motiv. Siguiendo en la misma obra El Estado de Sitio, la mejor señal de resquebrajamiento del mal que representa el personaje La Peste, llegaría en el momento que tal espíritu que se apreciaba inexpugnable se interrogue por el sentido real y profundo que le motiva. La Peste se resiente desde el momento que Diego le mira a los ojos, le enfrenta con orgullo y endereza: "por el camino que sigo no puede uno detenerse aunque se desee. ¡Ya no te evitaré!’(1050). La Peste piensa los fundamentos de su mal. La conciencia del rebelde quiebra la auto-complacencia del verdugo de saberse amo y destino a la vez, transparentándole lo fútil de su empresa al tratar administrar racionalmente la vida y la muerte. Diego logró des-fundamentar la maquinaria de muerte y de racionalidad nihilista que le sostenía. Desafiante afirma éste anti-héroe: "Sólo desprecio a los verdugos, si alguna vez matan lo hacen en estado de locura" (1055). Para Diego no se ha de temer lo que es fiel a la condición humana, lo que indigna más bien es la lógica que la sostiene. Saber vivir, es también saber morir para el antihéroe rebelde: "Tenía sed de honores ¿Y no los encontraré hoy sino entre los muertos? (1056). Diego comprende que la rebeldía puede cobrar sentido en los extremos del desprecio de la muerte impuesta. Es consciente que su triunfo radica en la conciencia de la muerte escogida y no bajo esa lógica artificiosa del "todo o nada". El saber morir es parte de la acción anti heroica rebelde que descompone el frenesí por el control total de los inquisidores, pues la consciencia de la propia finitud y su valoración es irreductible a todo afán absolutista.

En la misma obra teatral antes mencionada, la valentía y el sacrificio de Diego amedrentan a La Peste, pero también cuestionan a La Secretaria ante su naturaleza de muerte confrontada con su lógica nihilista: "Era libre, antes que usted estaba asociada al azar. Entonces nadie me detestaba" (1057). Diego triunfa en la tragedia y el honor que trae consigo el sacrificio en base a la propia justificación de la muerte. La voluntad de negación nihilista para Camus, en su vivencia extrema mostraría sus fisuras descubiertas por la futilidad de su misma empresa de destrucción nihilista: "Mi odio exige víctimas frescas. Despáchame ésta. Y volveremos a empezar en otra parte” (1057) afirma La Peste. No 
obstante ella misma advierte: "la crueldad subleva, pero la tontería descorazona ¡Honor a los estúpidos, pues ellos preparan mis caminos! ¡Constituyen mi fuerza y mi esperanza! (1060). La lógica de muerte desvelada en sus razones profundas cesa de ser campo fecundo para el nihilismo. La Nada, el personaje nihilista anónimo que habita en el alma de los desencantados, intensificado en sus ansías de destrucción por la llegada de la dictadura del mal, luego del fracaso termina arrojándose al mar. Enfriado el odio y sus razones queda sin sostén para su empresa de fundir "unidad y totalidad". La Peste en su retiro simboliza no una derrota definitiva, más bien sólo su aplacamiento momentáneo; en tanto La Nada como personificación singular del nihilismo anuncia: "Adiós buena gente; un día sabréis que no se puede vivir bien sabiendo que el hombre no es nada y que la cara de Dios es espantosa" (Camus 1065).

Lo anterior en Camus nos muestra cierta superación del nihilismo en sustento del desbaratamiento del odio y la artificiosa lógica de muerte por parte del antihéroe. El mal y el nihilismo se retiran de la escena humana, pero siguen latente en el olvido de vivir una humanidad consciente, ignorando la tensión entre dicha y muerte que implican asumir de forma extenuante y tensional una condición de finitud y carencia.

\section{Conclusiones.}

El anti heroísmo y el nihilismo que hemos analizado en este artículo, desde la obra pensamiento de Albert Camus, ha girado finalmente en torno al repliegue y despliegue de una voluntad nihilista cobijada inherentemente en el carácter desfondado de estos seres singulares, fronterizos y periféricos. Degradación moral y posterior reposición sensata de un valor humano, examinados desde su obra temprana o sensitiva entregada a la dicotomía del placer y la escasez; pasando luego por el absurdo de una disonancia existencial trasmutada en rebeldía hacia un mal de escala universal, que nos ofrece un sensato triunfo en la lucidez y conciencia de su misma intranscendencia. De ahí entonces la lucidez que asoma en su comprensión del mundo traducida en oscilaciones existenciales entre la afirmación y negación total. Antihéroes camusianos entregados al juego de perspectivas de corte nietzscheano que "juegan-seriamente" dentro de los ámbitos que su existencia despojada les circunscribe. Pero como apreciamos en nuestro análisis, para Camus en tal oscilación entre el sí y el no yace el peligro. La inclinación de estos personajes hacia la 
voluntad de negación ascética y purgativa, como hacia la vehemencia por el restablecimiento perentorio de sentido nos aproxima en ambos casos, a la presencia del peor de los huéspedes: el nihilismo. Y sin embargo, Camus nos dejaba entrever que la solidaridad resurgida con los hombres en la muerte y el dolor resaltan no sólo las antinomias inherentes de la naturaleza humana, sino con inusual fuerza nos muestran un sentido ético subyacente en todo caída abyecta.

En plena presencia nihilista apreciamos como el auténtico antihéroe camusiano si bien rechaza grandes verdades, como las divinas o históricas porque ve en ellas la plasmación de la muerte y el mal cobijada en complacientes discursos de conciliación universal, no puede negar su presencia ontológica, pues como acontece con la Historia: "se encuentra ante ella como el artista ante lo real, la rechaza sin eludirla" (El Hombre 143). Ello nos refiere la mesura como valor suscitado por toda auténtica rebelión del antihéroe: "La mesura es un conflicto constante, perpetuamente suscitado y dominado por la inteligencia. No triunfa ni de lo imposible ni del abismo. Se equilibra con ellos" (279). En tal sentido, el coro al final de la obra El Estado de Sitio nos advierte aquel sentido axiológico como límite que convive en la obra literaria de Camus, confrontado con la nítida descripción del escozor nihilista: "No, no hay justicia, pero hay límites. Y quienes pretenden no reglamentar nada los traspasan igual que aquellos que quieren dar reglas para todo" (1064). Ello nos llevaba a entender cierta "superación de nihilismo" por parte de la sensatez y mesura que establecerían lo antihéroes. Pareciera entonces, por el reconocimiento de Diego y su sacrificio como la lucidez de Rieux o Meursault, tal superación será tal si comprende una reconsideración de tales límites éticos. En relación a ello, en su Carnets II nos afirma Albert Camus: "si todos nosotros, que precedemos del nietzscheísmo, del nihilismo o del realismo histórico confesáramos públicamente que nos hemos equivocado, que existen valores morales y en lo sucesivo haremos lo que sea necesario para fundarlos o ilustrarlos, ¿esto podría ser el comienzo de una esperanza?"(143). En el extremo más desgarrador para la condición humana que infringe la voluntad nihilista sería posible apreciar, según lo examinamos en el Nobel francés, una fulgurante afirmación positiva que permanece incluso en esta embriaguez de aniquilación.

Descubrimiento de una moral de límites subyacente al anti heroísmo y su relación con el nihilismo, conducente sino a desestimar las verdades, sí mantenerse en vigilia 
permanente frente al nihilismo inherente en todo afán absolutista, como también frente a la desestimación de toda directriz moral. Vital mensaje expresado literariamente, de valor atemporal que nos ayudaría a resignificar los procesos de duelo en una sociedad que parece todavía no superar la nostalgia de los héroes y verdades aparentemente fenecidas.

\section{Bibliografías}

Aranguren, José Luis. Obras Completas, Vol. II. Madrid: Trotta, 1994.

Birnbaum, Antonia. Nietzsche. Las aventuras del heroísmo. Trad. Arturo Rocha. México: Fondo de Cultura económica, 2004.

Bobbio, Norberto. El existencialismo. México: Fondo de Cultura Económica, 1997.

Brisville, Jean Claude. Camus. Trad. Jorge Cruz. Buenos Aires, Argentina: Peuser, 1962.

Camus, Albert. Obras Completas. Tomo I, II. 2da. Edición. Trad. Federico Saínz de Robles. México D.F: Aguilar, 1961.

Camus, Albert. Carnets II. (Enero de 1942- marzo de 1951). Trad. Mariano Lencera. Buenos Aires, Argentina: Losada, 1966.

Camus, Albert. Teatro: El Malentendido, Calígula, El Estado de Sitio, Los Justos. 6a. Ed. Trad. Aurora Bernárdez y Guillermo De Torre. Buenos Aires, Argentina: Losada, 1968.

Camus, Albert. El Primer Hombre. Trad. Aurora Bernárdez. Barcelona: Tusquets, 1994.

Camus, Albert. El Hombre Rebelde. 14va. Ed. Trad. Luis Echávarri. Buenos Aires, Argentina: Losada, 2003.

Camus, Albert. El Extranjero. 10 reimpresiones. Trad. José Ángel Valente. España: Alianza-Emecé, 2004.

Camus, Albert. La Caída. Trad. Alberto Luis Bixio. España: Losada, 1996.

Camus, Albert. La Peste. 33va. Ed. Trad. Rosa Chacel. Buenos Aires, Argentina: Sudamericana, 2005.

Camus, Albert. El Mito de Sísifo. 19va. Ed. Trad. Luis Echeverri. Buenos Aires, Argentina: Losada, 2005.

Cejudo Borrega, Enrique. "Albert Camus y la filosofía del límite" (lectura casi nietzscheana del hombre rebelde). Revista Endoxa 17 (2003): 277- 296.

Cruickshank, John. El Novelista Filósofo. Buenos Aires, Argentina: Piados, 1968.

De Lupe, Robert. Albert Camus. Trad. Rafael Aragó. Buenos Aires, Argentina: La Mandrágora, 1952.

Fullat, Octavio. La Moral Atea de Albert Camus. Barcelona: Pubul, 1963.

Gallardo, Vidal Blas. Camus o la exigencia de los límites. Salamanca: Fundación Teresa de Jesús, 1998.

Heidegger, Martín. Ser y Tiempo. Trad. Eduardo Rivera. Santiago, Chile: Universitaria, 2015.

Hourdin, Georges. Camus el Justo. Trad. Monserrat Serra Cantarel. Barcelona: Estela, 1960.

Jasper, Karl. La Filosofía. Trad. José Gados. México: Fondo de Cultura Económica, 2003. 
Johnson, Paul. Tiempos Modernos, La Historia del Siglo XX (desde 1917 hasta la década de los 80). Buenos Aires, Argentina: Vergara, 1988.

Lévy Bernard-Henri. Las Aventuras de la libertad. Trad. Ignacio Echeverría. Barcelona: Anagrama, 1992.

Lottman, Helbert. Albert Camus. 1era. Ed. Trad. Amalia Alvarez. Madrid: Taurus, 1994.

Mailhot, Laurent. Albert Camus ou l' Imagination du Désert. Montréal: Presses de l' Université Montréal, 1973.

Mosciatti, Nibaldo. Ni víctimas ni verdugos: Apuntes sobre el viaje de Albert Camus a Chile. Santiago, Chile: Espíritu Libertario, 2003.

Mounier, Emmanuel. Introducción a los Existencialismos. Trad. Daniel Montserrat. Madrid: Guadarrama, 1973.

Vattimo, Gianni. El Fin de la Modernidad. Trad. Alberto Bixio. Barcelona: Gedisa, 1985.

Vatttimo, Gianni. Ética de la Interpretación. 1er. Ed. Trad. Teresa Oñate. Barcelona: Paidós, 1991.

Volpi, Franco. El Nihilismo. Buenos Aires, Argentina: Editorial Biblios, 2011. 